\title{
Prevalence and risk factors for unrecognized obstructive lung disease among urban drug users
}

This article was published in the following Dove Press journal: International Journal of Chronic Obstructive Pulmonary Disease I 8 January 201 I

Number of times this article has been viewed

\author{
M Bradley Drummond' \\ Gregory D Kirk ${ }^{1,2}$ \\ Jacquie Astemborski \\ Meredith C McCormack' \\ Mariah M Marshall ${ }^{2}$ \\ Shruti H Mehta ${ }^{2}$ \\ Robert A Wise' \\ Christian A Merlo' \\ 'Department of Medicine, \\ School of Medicine, ${ }^{2}$ Department \\ of Epidemiology, Bloomberg \\ School of Public Health, \\ Johns Hopkins University, \\ Baltimore, MD, USA
}

Correspondence: M Bradley Drummond Department of Medicine, School of Medicine, Johns Hopkins University, 550I Hopkins Bayview Circle, JHAAC 4B.70, Baltimore, MD 21224, USA

$\mathrm{Tel}+\mathrm{I} 4105500545$

Fax +I 4105377259

Email mdrummo3@jhmi.edu
Background: Obstructive lung disease (OLD) is frequently unrecognized and undertreated. Urban drug users are at higher risk for OLD due to race, behavioral, and socioeconomic characteristics, yet little data exist on prevalence and risk factors associated with unrecognized OLD in this population.

Objective: The objective of this study is to determine the prevalence of unrecognized OLD in an urban population and identify the characteristics associated with lack of physiciandiagnosed OLD.

Design: Cross-sectional analysis from the Acquired Immunodeficiency Syndrome Linked to the Intravenous Experience (ALIVE) study, an observational study of current and former injection drug users in Baltimore, Maryland, USA.

Participants: All participants with spirometry-defined airflow obstruction were stratified by the presence or absence of physician diagnosis of OLD.

Main measures: Using cross-sectional demographic, clinical, and spirometric measurements, multivariable regression models were generated to identify factors independently associated with unrecognized OLD.

Key results: Of the 1083 participants evaluated in the ALIVE lung substudy, 176 (16.3\%) met spirometric criteria for OLD. Of those, only 88 (50\%) had a physician diagnosis of OLD. The prevalence of unrecognized OLD decreased as severity of airflow obstruction increased. Factors independently associated with unrecognized OLD were absence of respiratory symptoms (prevalence ratio [PR], 1.70; 95\% confidence interval [CI]: 1.29-2.23; $P<0.01$ ) and less severe dyspnea (PR, $0.83 ; 95 \%$ CI: $0.72-0.96$, per point increase in dyspnea scale; $P=0.01$ ). In the subset of human immunodeficiency virus (HIV)-infected participants, the use of antiretroviral therapy (ART) was independently associated with an increased prevalence of unrecognized OLD (PR, 1.93; 95\% CI: 1.05-3.56; $P=0.03$ ).

Conclusions: In a cohort of current and former urban drug users, OLD is substantially underrecognized and associated with lack of respiratory symptoms. Relying on the presence of respiratory symptoms as a trigger to perform spirometry may result in a substantial underdiagnosis of OLD in this population. HIV-infected individuals receiving ART are a population particularly vulnerable to unrecognized OLD.

Keywords: obstructive lung disease, human immunodeficiency virus infection, COPD, asthma, spirometry

\section{Introduction}

Obstructive lung diseases (OLDs), specifically asthma and chronic obstructive pulmonary disease (COPD), are prevalent conditions associated with substantial morbidity and mortality in the United States. ${ }^{1-3}$ OLD is frequently unrecognized even in smokers. ${ }^{4-6}$ 
Several studies have identified populations at higher risk for unrecognized OLD including rural populations, ${ }^{7}$ the urban homeless, ${ }^{8}$ and medical inpatients. ${ }^{9}{ }^{910}$ Urban populations with a history of current or former drug use represent a poorly studied group with a substantial burden of tobacco abuse and lower socioeconomic status. ${ }^{11-13}$ There is an increased risk of human immunodeficiency virus (HIV) infection in the urban population, ${ }^{14,15}$ and HIV is associated with an increased prevalence of OLD. ${ }^{16-18}$ Each of these factors markedly increases the susceptibility of this population to OLD. ${ }^{19-21}$ Characterizing the prevalence of unrecognized OLD is relevant given that unrecognized OLD is often undertreated. . $^{82}$ It remains unclear what patient characteristics may be associated with unrecognized OLD, especially in high-risk populations.

The AIDS Linked to the Intravenous Experience (ALIVE) study has prospectively observed a cohort of intravenous drug users (IDUs) in Baltimore, Maryland, USA since 1988. ${ }^{23}$ This population has been previously recognized to have limited access and delayed care for HIV. ${ }^{24}$ We have described the substantial prevalence of respiratory symptoms in this population previously. ${ }^{25}$ Moreover, the heavy burden of smoking dependence in this cohort makes it an ideal population to examine issues related to undiagnosed OLD. Clinical and spirometric data have been collected on this cohort allowing for the determination of unrecognized OLD. In the current study, we use the cross-sectional data from the ALIVE study to determine the prevalence of unrecognized OLD in a large group of urban IDUs. We determine demographic and clinical factors associated with unrecognized OLD in this population.

\section{Methods}

\section{Setting and participants}

The methods for recruitment and data collection in the ALIVE study have been described previously. ${ }^{23}$ Briefly, ALIVE participants were recruited if they were aged $\geq 18$ years, living in inner-city Baltimore, Maryland, and injecting drugs at enrollment. As part of a lung disease substudy, ALIVE participants completed an extensive respiratory questionnaire and performed spirometry testing at a regularly scheduled ALIVE biannual visit. Cross-sectional demographic and clinical data collected at the time of the lung substudy evaluation (January 9, 2007-June 26, 2009) were included in this analysis. This study was approved by Institutional Review Board of the Johns Hopkins Bloomberg School of Public Health and Johns Hopkins University School of Medicine
(Protocol NA_00020295). All participants provided written informed consent.

For this analysis, all individuals with spirometry-defined obstruction (as defined below) were selected. An individual was defined as having recognized OLD if spirometric obstruction was present and the individual reported a physician diagnosis of asthma, chronic bronchitis, or emphysema. An individual was defined as having unrecognized OLD if spirometric obstruction was present and the individual reported no physician diagnosis of asthma, chronic bronchitis, or emphysema.

\section{Measurements}

Participants completed a modified version of the American Thoracic Society respiratory questionnaire. ${ }^{26}$ The questionnaire collected information regarding presence, frequency and timing of respiratory symptoms (cough, phlegm, and wheezing), and dyspnea. Absence of respiratory symptoms was defined as answering in the negative to usually having cough, usually bringing up phlegm, and ever wheezing. Dyspnea was assessed using the modified Medical Research Council (MRC) questionnaire with a validated 0-4 scale, with a higher score indicating worse dyspnea. ${ }^{27,28}$ Smoking status and duration, injection drug use in the last 6 months, and antiretroviral use were determined by self-report. Participants were asked if they had ever received a physician diagnosis of asthma, chronic bronchitis, or emphysema.

OLD was defined as a prebronchodilator ratio of forced expiratory volume in one second $\left(\mathrm{FEV}_{1}\right)$ with forced vital capacity (FVC) of $<0.70$. Severity of spirometric obstruction was defined by using the Global Initiative for Obstructive Lung Disease criteria: mild ( $\mathrm{FEV}_{1} \geq 80 \%$ predicted), moderate $\left(\mathrm{FEV}_{1}=50 \%-79 \%\right.$ predicted $)$, severe $\left(\mathrm{FEV}_{1}=30 \%-49 \%\right.$ predicted $)$, and very severe $\left(\mathrm{FEV}_{1}<30 \%\right.$ predicted $) .{ }^{1}$ Percent predicted values and lower limit of normal (LLN) criteria were calculated using standard formulas. ${ }^{29}$ Spirometry was performed using a $\mathrm{KOKO}^{\circledR}$ (Pulmonary Data Services, Inc, Louisville, CO) pneumotach in accordance with American Thoracic Society guidelines. ${ }^{30}$

\section{Statistical analysis}

Clinical and demographic characteristics between groups were presented as mean (standard deviation), median (interquartile range $[\mathrm{IQR}])$, or $\mathrm{n}(\%)$. Continuous variables were compared using $t$-test for normally distributed data and Wilcoxon-Mann-Whitney test for skewed data. Categorical variables were compared with Pearson's $\chi^{2}$ test. Because odds 
ratios can overestimate the magnitude of association between covariates and the outcome of interest in cross-sectional studies when the prevalence of the outcome exceeds 20\%, ${ }^{31-33}$ univariate and adjusted prevalence ratios (PR) with 95\% confidence intervals (95\% CI) were generated using Poisson regression models with robust variance. ${ }^{34,35}$ Covariates were evaluated based upon biological plausibility and inspection of exploratory data analyses. Prevalence of unrecognized obstruction stratified by disease severity was compared using Pearson's $\chi^{2}$ test. Stata software (version 10.0; Stata Corp, College Station, TX) was used for statistical analysis.

\section{Results}

\section{Prevalence and correlates of unrecognized OLD}

Of the 1083 participants evaluated in the ALIVE lung substudy, 176 (16.3\%) participants met criteria for spirometric obstruction. Only 88 (50\%) participants with OLD had a physician diagnosis of OLD. Among participants with recognized OLD, 51 (58\%) had a physician diagnosis of asthma only, 13 (15\%) COPD only, and 24 (27\%) reported both asthma and COPD. As a comparison, of the 907 participants with normal pulmonary function, $213(23 \%)$ reported a physician diagnosis of OLD. Of these, 120 (56\%) had a physician diagnosis of asthma only, 60 (28\%) COPD only, and $33(16 \%)$ reported both asthma and COPD. The mean age of participants with spirometric obstruction was 50 years, nearly $70 \%$ were male and $85 \%$ were black (Table 1 ). A total of $155(88 \%)$ participants were current smokers with a median pack-years of 22 . Approximately $40 \%$ reported injection drug use in the previous 6 months. Nearly $30 \%$ were HIV-positive, with a median CD4 count of 331 cells $/ \mathrm{mm}^{3}$. Of HIV-infected subjects, $51 \%$ had been using antiretrovirals in the last 6 months. The prevalence of OLD did not differ by HIV status (16.5\% HIV-infected vs $16.2 \%$ HIV-uninfected individuals; $P=0.89$ ) or current injection drug use status (15.7\% current users vs $16.6 \%$ prior users; $P=0.70)$. Participants with unrecognized OLD were more frequently male when compared to those with recognized OLD $(80 \%$ vs $55 \% ; P<0.01)$. The prevalence of unrecognized OLD did not differ by pack-years smoking history. Aside from gender, demographic and clinical characteristics were similar between those with recognized and unrecognized OLD.

Respiratory symptoms were common in the cohort, with 74\% reporting cough, wheeze, or phlegm (Table 2). Respiratory symptoms were less frequent in individuals with unrecognized OLD. A total of 50 (57\%) participants with unrecognized OLD reported any respiratory symptoms compared with $81(92 \%)$ participants with recognized OLD $(P<0.01)$. The frequencies of individual symptoms of cough, wheeze, and phlegm were all lower in individuals with unrecognized OLD. Less severe dyspnea, represented by lower MRC scores, was present in participants with unrecognized OLD.

Table I Demographic and clinical characteristics of study participants

\begin{tabular}{|c|c|c|c|c|}
\hline & Overall & Recognized OLD & Unrecognized OLD & $P$ value $^{\mathrm{a}}$ \\
\hline $\mathrm{N}$ & 176 & 88 & 88 & \\
\hline Age (years) & $49.6(8.9)$ & $49.9(8.47)$ & $49.4(9.31)$ & 0.74 \\
\hline Male, n (\%) & $118(67.1)$ & $48(54.6)$ & $70(79.6)$ & $<0.01$ \\
\hline Black race/ethnicity, n (\%) & $149(84.7)$ & $74(84.1)$ & $75(85.2)$ & 0.83 \\
\hline BMI $\left(\mathrm{kg} / \mathrm{m}^{2}\right)$ & $23.9(21.5-28.1)$ & $23.8(21.5-28.8)$ & $24.1(21.6-28.0)$ & 0.77 \\
\hline Completed high school education, n (\%) & $68(38.6)$ & $36(40.9)$ & $32(36.4)$ & 0.54 \\
\hline \multicolumn{5}{|l|}{ Smoking status, n (\%) } \\
\hline Current & I $55(88.1)$ & $78(88.6)$ & $77(87.5)$ & \\
\hline Former & $15(8.5)$ & $7(8.0)$ & $8(9.1)$ & \\
\hline Never & $6(3.4)$ & $3(3.4)$ & $3(3.4)$ & 0.96 \\
\hline Smoking, pack-years & $22(14-39)$ & $23.5(|3.5-4| .0)$ & $21.5(\mid 4.5-38.0)$ & 0.69 \\
\hline IDU, n (\%) & $71(40.3)$ & $37(42.1)$ & $34(38.6)$ & 0.65 \\
\hline HIV-infected, n (\%) & $51(29.0)$ & $28(31.8)$ & $23(26.2)$ & 0.41 \\
\hline CD4 count (cells $\left./ \mathrm{mm}^{3}\right)^{c}$ & $33 \mid(|68-49|)$ & 298 (I74-489) & $380(|6|-574)$ & 0.56 \\
\hline Viral load undetectable, $\mathrm{n}(\%)^{c}$ & $25(49.0)$ & $13(46.4)$ & $12(52.2)$ & 0.68 \\
\hline Viral load $\left(\log _{10}\right)^{\mathrm{d}}$ & $4.23(3.18-5.33)$ & $2.85(2.60-4.42)$ & $2.60(2.60-4.02)$ & 0.60 \\
\hline Antiretroviral use, $\mathrm{n}(\%)^{\mathrm{b}}$ & $26(51.0)$ & II (39.9) & $15(65.2)$ & 0.07 \\
\hline
\end{tabular}

Notes: aP value comparing recognized to unrecognized OLD categories; 'bln prior 6 months; 'Mean (SD) or n (\%) of HIV-infected participants only; ${ }^{\mathrm{A} A m o n g}$ HIV-infected individuals with detectable viral load.

Abbreviations: OLD, obstructive lung disease; BMI, body mass index; IDU, injection drug use; HIV, human immunodeficiency virus. 
Table 2 Respiratory symptoms and dyspnea measures of study participants

\begin{tabular}{|c|c|c|c|c|}
\hline & Overall & Recognized OLD & Unrecognized OLD & P value \\
\hline $\mathrm{N}$ & 176 & 88 & 88 & \\
\hline \multicolumn{5}{|l|}{ Respiratory symptoms } \\
\hline Any ${ }^{\mathrm{b}}$ & I3I (74.4) & $81(92.1)$ & $50(56.8)$ & $<0.01$ \\
\hline Usually have cough & $82(46.6)$ & $53(60.2)$ & $29(33.0)$ & $<0.01$ \\
\hline Ever wheeze & $105(59.7)$ & $72(81.8)$ & $33(37.5)$ & $<0.01$ \\
\hline Usually have phlegm & $85(48.2)$ & $55(62.5)$ & $30(34.1)$ & $<0.01$ \\
\hline \multicolumn{5}{|l|}{ MRC score } \\
\hline 0 & $108(6 \mid .4)$ & $4 \mid(46.6)$ & $67(76.1)$ & \\
\hline 1 & $14(8.0)$ & $6(6.8)$ & $8(9.1)$ & \\
\hline 2 & $10(5.7)$ & $7(8.0)$ & $3(3.4)$ & \\
\hline 3 & $19(10.8)$ & $12(13.6)$ & $7(8.0)$ & \\
\hline 4 & $25(14.2)$ & $22(25.0)$ & $3(3.4)$ & $<0.01$ \\
\hline
\end{tabular}

Notes: ap value comparing recognized to unrecognized OLD categories; 'bny respiratory symptoms include any report of usually having cough, usually bring up phlegm, or ever wheezing.

Abbreviations: OLD, obstructive lung disease; MRC, Medical Research Council.

\section{Effect of disease severity on OLD recognition}

The median $\mathrm{FEV}_{1} / \mathrm{FVC}$ ratio of the study sample was 0.65 (IQR: $0.60-0.68$ ) with a mean $\mathrm{FEV}_{1} \%$ predicted of $71.7 \% \pm$ $18.8 \%$. Overall, 65 (37\%) had mild obstruction, 90 (51\%) had moderate obstruction, 17 (10\%) had severe obstruction, and $4(2 \%)$ had very severe obstruction. The mean $\mathrm{FEV}_{1} \%$ predicted was higher in participants with unrecognized OLD when compared to recognized OLD (77.9 \pm 19 vs $65.5 \pm 20$; $P=0.04)$. To determine if the prevalence of unrecognized OLD differed by categories of disease severity, the 176 participants were stratified by $\mathrm{FEV}_{1}$ into four groups: mild $(n=65)$, moderate $(n=90)$, severe $(n=17)$, and very severe $(n=4)$. The prevalence of unrecognized OLD decreased as severity of airflow obstruction increased (Figure 1). Of the 65 subjects with mild OLD, 44 (68\%) had unrecognized OLD, whereas 40 (44\%) of the 90 participants with moderate obstruction were unrecognized. Of the 17 subjects with severe obstruction, 4 (24\%) were unrecognized. None of the subjects with very severe obstruction were unrecognized.

\section{Factors independently associated with unrecognized OLD}

Univariate and multivariate Poisson regression analyses were performed to explore relationships between demographic and clinical factors and unrecognized OLD (Table 3). After accounting for relevant demographic and clinical characteristics, lack of respiratory symptoms and milder dyspnea were independently associated with an increase in the prevalence of unrecognized OLD. The absence of any respiratory symptoms was independently associated with a $70 \%$ increase in the prevalence of unrecognized OLD (PR, 1.70; 95\% CI: 1.29-2.23; $P<0.01$ ). Each point increase in the MRC score (indicating worse dyspnea) was associated with $\sim 20 \%$ reduction in the prevalence of unrecognized OLD (PR, 0.83; 95\% CI: $0.72-0.96 ; P=0.01$ ). These findings persisted after adjusting for HIV infection, current employment, and high school education.

To explore the potential association between treatment for HIV and recognition of OLD, the subset of 51 HIV-infected individuals with OLD were analyzed separately. After adjusting for baseline characteristics, respiratory symptoms, and MRC scores in this subset, the use of ART in the last 6 months was associated with an increased prevalence of unrecognized OLD (PR, 1.94; 95\% CI: $1.05-3.56 ; P=0.03$ ). This

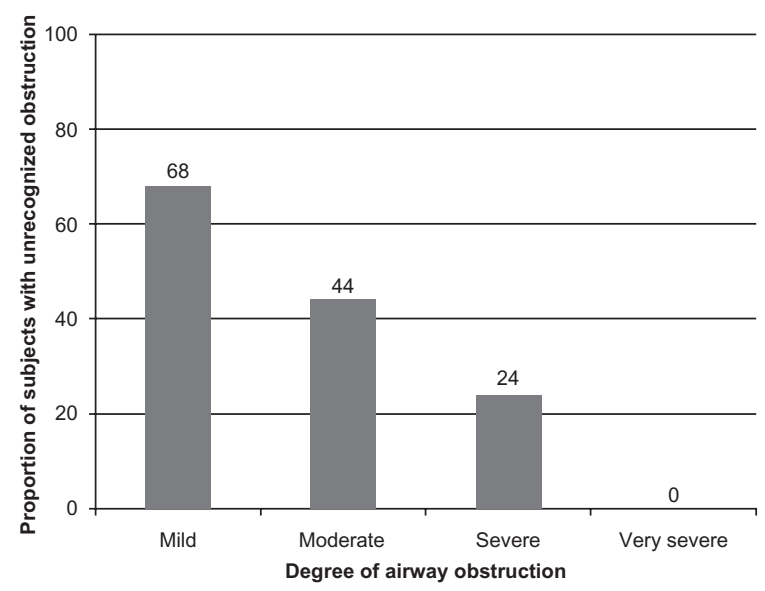

Figure I Prevalence of unrecognized OLD based on severity of airway obstruction. The 176 subjects were stratified by $\mathrm{FEV}$, into four groups: mild ( $\geq 80 \%$ predicted; $n=65)$, moderate $(50 \%-79 \%$ predicted; $n=90)$, severe $(30 \%-49 \%$ predicted; $n=17)$, and very severe $(<30 \%$ predicted; $n=4)$. Height of bar and data labels represents proportion of subjects in that stratum of OLD severity.

Abbreviations: $\mathrm{FEV}_{1}$, forced expiratory volume in the one second; OLD, obstructive lung disease. 
Table 3 Factors associated with unrecognized obstructive lung disease $(n=176)$

\begin{tabular}{|c|c|c|c|c|}
\hline Predictors & $\begin{array}{l}\text { Unadjusted prevalence } \\
\text { ratio }(95 \% \mathrm{Cl})\end{array}$ & $P$ value & $\begin{array}{l}\text { Adjusted prevalence } \\
\text { ratio }^{\mathrm{a}}(95 \% \mathrm{Cl})\end{array}$ & $P$ value \\
\hline Age (per 10 years) & $0.98(0.82-1.15)$ & 0.73 & $0.88(0.74-1.08)$ & 0.24 \\
\hline Male gender & $1.91(1.26-2.89)$ & $<0.01$ & $1.47(0.97-2.22)$ & 0.07 \\
\hline Race (black vs nonblack) & $1.05(0.68-1.60)$ & 0.84 & $1.34(0.90-2.00)$ & 0.15 \\
\hline High school education & $0.91(0.66-1.24)$ & 0.54 & $0.85(0.64-1.12)$ & 0.25 \\
\hline Pack-years (per 10 pack-years) ${ }^{b}$ & $0.96(0.88-1.04)$ & 0.33 & $1.00(0.92-1.09)$ & 0.94 \\
\hline HIV infection & $0.87(0.6 \mathrm{I}-\mathrm{I} .23)$ & 0.42 & $0.88(0.64-1.20)$ & 0.42 \\
\hline FEV (per 10\% predicted) & $1.21(1.11-1.32)$ & $<0.01$ & $1.07(0.97-1.18)$ & 0.15 \\
\hline No respiratory symptoms & $2.21(1.72-2.85)$ & $<0.01$ & $1.70(1.29-2.23)$ & $<0.01$ \\
\hline MRC score (per point increase) & $0.74(0.64-0.86)$ & $<0.01$ & $0.83(0.72-0.96)$ & 0.01 \\
\hline
\end{tabular}

Notes: aPrevalence ratio adjusted for other predictors in table; 'Pack-years calculated as number of packs per day $\times$ number of years smoking.

Abbreviations: HIV, human immunodeficiency virus; $\mathrm{FEV}_{1}$, forced expiratory volume in the one second; MRC, Medical Research Council.

association was attenuated when incorporating \% predicted $\mathrm{FEV}_{1}$ into the adjusted model (PR, 1.79; 95\% CI: 0.99-3.26; $P=0.055)$.

\section{Discussion}

In this study of OLD in an urban cohort of former and current IDUs, we have found that the prevalence of unrecognized OLD is very high, with half of participants with spirometric obstruction lacking a physician diagnosis. The prevalence of unrecognized OLD was highest among participants with milder degrees of airway obstruction. Lack of respiratory symptoms and less severe dyspnea were independently associated with unrecognized OLD in this population after accounting for severity of airway obstruction. The use of antiretroviral therapy (ART) in HIV-infected participants was associated with an increased prevalence of unrecognized OLD.

Our observation of a substantial underrecognition of OLD in this cohort identifies the urban IDU population as a group particularly susceptible to undiagnosed OLD. We observed a $50 \%$ prevalence of unrecognized OLD, higher than that observed in rural, medical inpatient, and Spanish communitybased populations. ${ }^{7,9,36}$ Based on our findings, prevalence estimates of disease burden from OLD are likely to be significantly underestimated in the urban IDU population.

Because use of a fixed ratio to define OLD may result in overdiagnosis of disease in a younger population, we also evaluated this cohort using a LLN criteria ${ }^{29}$ to define OLD. Although an additional nine participants were defined as having OLD using LLN criteria, the prevalence of unrecognized OLD did not differ (50\%).

Several reasons may exist for the high prevalence of unrecognized OLD in this population. Urban populations may have fewer primary health care encounters, ${ }^{37}$ the time at which spirometric testing is most likely to occur. ${ }^{38,39}$ Primary care providers who care for such individuals may attend to more overt symptoms and diseases at a particular health care encounter, thereby leaving OLD unrecognized. ${ }^{40}$ Our observation that ART use is associated with a higher prevalence of unrecognized OLD in HIV-infected participants suggests that physicians may focus on HIV-related illnesses, deferring non-HIV-related diagnoses such as OLD for subsequent encounters. Alternatively, individuals with more severe OLD (and therefore more frequently recognized OLD) may represent a cohort less likely to access HIV care. The prevalence of unrecognized OLD is similar to that observed in an analysis of the general population. ${ }^{41}$ However, unlike the general population, the urban population is exposed to increased risk factors for OLD and the difficulty in access to care. Therefore, aggressive spirometric screening programs for at-risk individuals may allow for earlier detection and subsequent lifestyle modification and treatment of OLD in the urban population.

In our analysis, lack of symptoms was a strong independent factor associated with unrecognized OLD. Several studies have explored the long-term outcomes of individuals with asymptomatic OLD, reaching conflicting results. Bridevaux and colleagues demonstrated that individuals with mild COPD who lack respiratory symptoms have long-term decline in $\mathrm{FEV}_{1}$ and health care utilization similar to symptomfree individuals without OLD. ${ }^{42}$ However, in a young community-based cohort, Mannino and colleagues have shown that individuals with symptom-free moderate OLD have a $60 \%$ increase in the risk of death (hazard ratio [HR], 1.6; 95\% CI: 1.3-2.1) when compared to healthy individuals. ${ }^{43}$ The risk of death in moderate COPD further increases when symptoms are present (HR, 2.1; 95\% CI: 1.7-2.6). These data suggest that the one-quarter of our participants with 
unrecognized moderate OLD represent a group at increased risk of death, regardless of the presence of symptoms. Relying strictly on presence of respiratory symptoms as a trigger to perform spirometry in at-risk individuals may result in a substantial underdiagnosis of OLD and a missed opportunity to intervene with smoking cessation programs and pharmacological treatments in a group with increased mortality. Tobacco use has been shown to be a distal predictor of mortality among long-term narcotic addicts. ${ }^{44,45}$ Studies suggest that awareness of airflow obstruction among smokers enhances smoking cessation rates. ${ }^{46,47}$ Thus, decreasing the prevalence of unrecognized OLD may enhance smoking cessation and survival in this population.

Although the presence of OLD does not mandate pharmacological interventions, especially in the case of mild disease with few symptoms, lifestyle modifications to prevent progression of disease are of benefit. ${ }^{1}$ Although current data do not suggest that inhaled pharmacotherapies substantially alter the decline of $\mathrm{FEV}_{1}$ or mortality, these agents are effective at controlling symptoms and exacerbations associated with OLD. ${ }^{1}$ Given the substantial proportion of participants with unrecognized OLD reporting symptoms of cough, wheeze, or phlegm, there exists a potential improvement in quality of life with making the diagnosis and treatment of OLD in an urban population of IDUs.

Our study has some limitations. We do not have data on pre- and postbronchodilator reversibility to allow for distinction between reversible and fixed airways obstruction. However, the use of consistent, standardized spirometry measurements allows us to make valid classification of the presence of OLD. Additionally, we did not collect data on other lung diseases (eg, bronchiectasis) which may impact the diagnosis of OLD. Although our findings are valid for an urban population of IDUs, they may not be generalizable to the urban population at large or other communities. Despite these limitations, the standardized and extensive data collection used for this analysis allows us to make valid conclusions regarding unrecognized OLD in a high-risk population.

In summary, we have observed a high prevalence of unrecognized OLD in an urban population of former and current IDUs. Lack of respiratory symptoms and milder dyspnea were independently associated with unrecognized OLD. HIV-infected individuals receiving ART are a population particularly vulnerable to unrecognized OLD. These findings emphasize the marked underrecognition of a chronic yet treatable condition in a particularly vulnerable population.
Individual practitioners and health care policy groups should use this information to help develop OLD detection, prevention, and treatment strategies for individuals in urban centers.

\section{Acknowledgments}

This study was funded in part by grants from the National Institutes of Health (Grants HL090483, DA04334, and DA12568). Dr Drummond is funded by a grant from the National Institutes of Health, National Heart, Lung and Blood Institute (K23HL103192). Portions of this manuscript were presented at the International Conference of the American Thoracic Society in May 2010.

\section{Disclosure}

The authors report no conflicts of interest in this work.

\section{References}

1. Gomez FP, Rodriguez-Roisin R. Global Initiative for Chronic Obstructive Lung Disease (GOLD) guidelines for chronic obstructive pulmonary disease. Curr Opin Pulm Med. 2002;8(2):81-86.

2. McHugh MK, Symanski E, Pompeii LA, Delclos GL. Prevalence of asthma among adult females and males in the United States: results from the National Health and Nutrition Examination Survey (NHANES), 2001-2004. J Asthma. 2009;46(8):759-766.

3. Mannino DM, Homa DM, Akinbami LJ, Moorman JE, Gwynn C, Redd SC. Surveillance for asthma-United States, 1980-1999. MMWR Surveill Summ. 2002;51(1):1-13.

4. Mannino DM. COPD: epidemiology, prevalence, morbidity and mortality, and disease heterogeneity. Chest. 2002;121 (Suppl 5): 121S-126S

5. Banerjee DK, Lee GS, Malik SK, Daly S. Underdiagnosis of asthma in the elderly. Br J Dis Chest. 1987;81(1):23-29.

6. Renwick DS, Connolly MJ. Prevalence and treatment of chronic airways obstruction in adults over the age of 45. Thorax. 1996;51(2): 164-168.

7. Dales RE, Aaron SD, Vandemheen KL, Mehdizadeh A, Clinch J. The prevalence of airflow obstruction in rural primary care. Respir Med. 2006;100(4):754-759.

8. Snyder LD, Eisner MD. Obstructive lung disease among the urban homeless. Chest. 2004;125(5):1719-1725.

9. Zaas D, Wise R, Wiener C. Airway obstruction is common but unsuspected in patients admitted to a general medicine service. Chest. 2004; 125(1):106-111.

10. Damarla M, Celli BR, Mullerova HX, Pinto-Plata VM. Discrepancy in the use of confirmatory tests in patients hospitalized with the diagnosis of chronic obstructive pulmonary disease or congestive heart failure. Respir Care. 2006;51(10):1120-1124.

11. Schoener EP, Hopper JA, Pierre JD. Injection drug use in North America. Infect Dis Clin North Am. 2002;16(3):535-551, vii.

12. Marshall MM, McCormack MC, Kirk GD. Effect of cigarette smoking on HIV acquisition, progression, and mortality. AIDS Educ Prev. 2009; 21 (Suppl 3):28-39.

13. Inner-city health care. American College of Physicians. Ann Intern Med. 1997;126(6):485-490.

14. Alcabes P, Friedland G. Injection drug use and human immunodeficiency virus infection. Clin Infect Dis. 1995;20(6):1467-1479.

15. Holmberg SD. The estimated prevalence and incidence of HIV in 96 large US metropolitan areas. Am J Public Health. 1996;86(5):642-654. 
16. Crothers K, Butt AA, Gibert CL, Rodriguez-Barradas MC, Crystal S, Justice AC. Increased COPD among HIV-positive compared to HIVnegative veterans. Chest. 2006;130(5):1326-1333.

17. Beck JM, Rosen MJ, Peavy HH. Pulmonary complications of HIV infection. Report of the Fourth NHLBI Workshop. Am J Respir Crit Care Med. 2001;164(11):2120-2126.

18. Diaz PT, King MA, Pacht ER, et al. Increased susceptibility to pulmonary emphysema among HIV-seropositive smokers. Ann Intern Med. 2000;132(5):369-372.

19. Sherman CB, Hudson LD, Pierson DJ. Severe precocious emphysema in intravenous methylphenidate (Ritalin) abusers. Chest. 1987;92(6): 1085-1087.

20. Overland ES, Nolan AJ, Hopewell PC. Alteration of pulmonary function in intravenous drug abusers. Prevalence, severity, and characterization of gas exchange abnormalities. Am J Med. 1980;68(2):231-237.

21. Byrd RS, Joad JP. Urban asthma. Curr Opin Pulm Med. 2006;12(1): 68-74.

22. Nascimento OA, Camelier A, Rosa FW, Menezes AM, Perez-Padilla R, Jardim JR. Chronic obstructive pulmonary disease is underdiagnosed and undertreated in Sao Paulo (Brazil): results of the PLATINO study. Braz J Med Biol Res. 2007;40(7):887-895.

23. Vlahov D, Anthony JC, Munoz A, et al. The ALIVE study, a longitudinal study of HIV-1 infection in intravenous drug users: description of methods and characteristics of participants. NIDA Res Monogr. 1991; 109:75-100.

24. Celentano DD, Galai N, Sethi AK, et al. Time to initiating highly active antiretroviral therapy among HIV-infected injection drug users. AIDS 2001;15(13):1707-1715

25. Drummond MB, Kirk GD, Ricketts EP, et al. Cross sectional analysis of respiratory symptoms in an injection drug user cohort: the impact of obstructive lung disease and HIV. BMC Pulm Med. 10:27.

26. Ferris BG. Epidemiology standardization project (American Thoracic Society). Am Rev Respir Dis. 1978;118(6 Pt 2):1-120.

27. Fletcher CM. The clinical diagnosis of pulmonary emphysema; an experimental study. Proc R Soc Med. 1952;45(9):577-584.

28. Bestall JC, Paul EA, Garrod R, Garnham R, Jones PW, Wedzicha JA. Usefulness of the Medical Research Council (MRC) dyspnoea scale as a measure of disability in patients with chronic obstructive pulmonary disease. Thorax. 1999;54(7):581-586.

29. Hankinson JL, Odencrantz JR, Fedan KB. Spirometric reference values from a sample of the general US population. Am J Respir Crit Care Med. 1999;159(1):179-187.

30. Miller MR, Hankinson J, Brusasco V, et al. Standardisation of spirometry. Eur Respir J. 2005;26(2):319-338.

31. Thompson ML, Myers JE, Kriebel D. Prevalence odds ratio or prevalence ratio in the analysis of cross sectional data: what is to be done? Occup Environ Med. 1998;55(4):272-277.

32. Barros AJ, Hirakata VN. Alternatives for logistic regression in crosssectional studies: an empirical comparison of models that directly estimate the prevalence ratio. BMC Med Res Methodol. 2003;3:21.
33. Schiaffino A, Rodriguez M, Pasarin MI, Regidor E, Borrell C, Fernandez E. Odds ratio or prevalence ratio? Their use in cross-sectional studies [in Spanish]. Gac Sanit. 2003;17(1):70-74.

34. Behrens T, Taeger D, Wellmann J, Keil U. Different methods to calculate effect estimates in cross-sectional studies. A comparison between prevalence odds ratio and prevalence ratio. Methods Inf Med. 2004; 43(5):505-509.

35. Zou G. A modified poisson regression approach to prospective studies with binary data. Am J Epidemiol. 2004;159(7):702-706.

36. Miravitlles M, Soriano JB, Garcia-Rio F, et al. Prevalence of COPD in Spain: impact of undiagnosed COPD on quality of life and daily life activities. Thorax. 2009;64(10):863-868.

37. Juday TR, Wu A, Celentano DD, Frick KD, Wang MC, Vlahov D. The role of Medicaid HMO enrollment in the longitudinal utilization of medical care services in a cohort of injecting drug users in Baltimore, Maryland. Subst Abus. 2003;24(1):27-41.

38. Fiscella K, Franks P, Gold MR, Clancy CM. Inequality in quality: addressing socioeconomic, racial, and ethnic disparities in health care JAMA. 2000;283(19):2579-2584.

39. Van der Molen T, Schokker S. Primary prevention of chronic obstructive pulmonary disease in primary care. Proc Am Thorac Soc. 2009;6(8): 704-706.

40. Vogeli C, Shields AE, Lee TA, et al. Multiple chronic conditions: prevalence, health consequences, and implications for quality, care management, and costs. J Gen Intern Med. 2007;22 Suppl 3: 391-395.

41. Mannino DM, Gagnon RC, Petty TL, Lydick E. Obstructive lung disease and low lung function in adults in the United States: data from the National Health and Nutrition Examination Survey, 1988-1994. Arch Intern Med. 2000;160(11):1683-1689.

42. Bridevaux PO, Gerbase MW, Probst-Hensch NM, Schindler C, Gaspoz JM, Rochat T. Long-term decline in lung function, utilisation of care and quality of life in modified GOLD stage 1 COPD. Thorax. 2008;63(9):768-774.

43. Mannino DM, Doherty DE, Sonia Buist A. Global Initiative on Obstructive Lung Disease (GOLD) classification of lung disease and mortality: findings from the Atherosclerosis Risk in Communities (ARIC) study. Respir Med. 2006;100(1):115-122.

44. Hser YI, McCarthy WJ, Anglin MD. Tobacco use as a distal predictor of mortality among long-term narcotics addicts. Prev Med. 1994;23(1): 61-69.

45. Hurt RD, Offord KP, Croghan IT, et al. Mortality following inpatient addictions treatment. Role of tobacco use in a community-based cohort. JAMA. 1996;275(14):1097-1103.

46. Bednarek M, Gorecka D, Wielgomas J, et al. Smokers with airway obstruction are more likely to quit smoking. Thorax. 2006;61(10) 869-873.

47. Parkes G, Greenhalgh T, Griffin M, Dent R. Effect on smoking quit rate of telling patients their lung age: the Step2quit randomised controlled trial. BMJ. 2008;336(7644):598-600.
International Journal of COPD

\section{Publish your work in this journal}

The International Journal of COPD is an international, peer-reviewed journal of therapeutics and pharmacology focusing on concise rapid reporting of clinical studies and reviews in COPD. Special focus is given to the pathophysiological processes underlying the disease, intervention programs, patient focused education, and self management

\section{Dovepress}

protocols. This journal is indexed on PubMed Central, MedLine and CAS. The manuscript management system is completely online and includes a very quick and fair peer-review system, which is all easy to use. Visit http://www.dovepress.com/testimonials.php to read real quotes from published authors. 